\title{
Migraine and the risk of post-traumatic stress disorder among a cohort of pregnant women
}

\author{
Lauren E. Friedman ${ }^{1 *}$, Christina Aponte ${ }^{2 \dagger}$, Rigoberto Perez Hernandez ${ }^{2 \dagger}$, Juan Carlos Velez ${ }^{3}$, Bizu Gelaye ${ }^{1,4}$,
} Sixto E. Sánchez ${ }^{5,6}$, Michelle A. Williams ${ }^{1}$ and B. Lee Peterlin ${ }^{7}$

\begin{abstract}
Background: Individually both migraine and post-traumatic stress disorder (PTSD) prevalence estimates are higher among women. However, there is limited data on the association of migraine and PTSD in women during pregnancy.

Methods: We examined the association between migraine and PTSD among women attending prenatal clinics in Peru. Migraine was characterized using the International Classification of Headache Disorders (ICHD)-III beta criteria. PTSD was assessed using the PTSD Checklist-Civilian Version (PCL-C). Multivariable logistic regression analyses were performed to estimate odds ratios (OR) and 95\% confidence intervals (Cl) after adjusting for confounders.

Results: Of the 2922 pregnant women included, 33.5\% fulfilled criteria for any migraine (migraine 12.5\%; probable migraine $21.0 \%$ ) and $37.4 \%$ fulfilled PTSD criteria. Even when controlling for depression, women with any migraine had almost a 2-fold increased odds of PTSD (OR: 1.97; 95\% Cl: 1.64-2.37) as compared to women without migraine. Specifically, women with migraine alone (i.e. excluding probable migraine) had a 2.85 -fold increased odds of PTSD (95\% Cl: 2.18-3.74), and women with probable migraine alone had a 1.61 -fold increased odds of PTSD (95\% Cl: 1.30-1.99) as compared to those without migraine, even after controlling for depression. In those women with both migraine and comorbid depression, the odds of PTSD in all migraine categories were even further increased as compared to those women without migraine.

Conclusion: In a cohort of pregnant women, irrespective of the presence or absence of depression, the odds of PTSD is increased in those with migraine. Our findings suggest the importance of screening for PTSD, specifically in pregnant women with migraine.
\end{abstract}

Keywords: Migraine, Post-traumatic stress disorder, PTSD, Pregnancy

\section{Background}

According to the National Health Interview Survey in 2011, 26.1\% of women 18-44 years of age reported migraines or severe headaches in the last 3 months [1]. Migraine is more prevalent among reproductive-aged women as compared to men [2] and from early to middle adulthood as compared to younger or older individuals [1]. Migraine also often adversely affects the health of large

\footnotetext{
* Correspondence: Ifriedm@hsph.harvard.edu

${ }^{\dagger}$ Equal contributors

'Department of Epidemiology, Harvard T. H. Chan School of Public Health, 677 Huntington Ave, K501, Boston, MA 02115, USA

Full list of author information is available at the end of the article
}

populations [3]. Further, migraine in pregnancy is associated with an increased risk of perinatal complications including preeclampsia $[4,5]$, preterm delivery $[6]$, placental abruption [7], hypertensive disorders [6], as well as cardiovascular disease and stroke [8-11].

Maternal mood and anxiety disorders have been implicated as important risk factors for migraine [12-16]. Migraine during pregnancy is associated with an increased risk of depression [17, 18] and suicidal ideation [19]. Additionally, both migraine and PTSD are more prevalent in reproductive-aged women as compared to men $[2,3]$. Although increasing data supports an association between posttraumatic stress disorder (PTSD) and migraine in U.S. cohorts $[3,20,21]$, no prior study has examined the risk 
of PTSD in pregnant women. Further there is little evidence for the association between migraine and PTSD in women from low income countries or the impact of depression on this association. To fill in these gaps in the literature, we examined the association between migraine and PTSD among a cohort of pregnant women in Lima, Peru.

\section{Methods}

\section{Study population}

The study population for this cross-sectional study was drawn from participants of the Pregnancy Outcomes, Maternal and Infant Study (PrOMIS) cohort. The PrOMIS cohort has been described previously [22-25]. The cohort was designed to examine maternal social and behavioral risk factors on the development of preterm birth and other adverse pregnancy outcomes among Peruvian women. The PrOMIS cohort was comprised of women attending prenatal care clinics at the Instituto Nacional Materno Perinatal (INMP) in Lima, Peru. INMP is operated by the Peruvian government and is the primary reference establishment for maternal and perinatal care. Women were eligible for inclusion if they initiated prenatal care before 16 weeks of gestation, were at least 18 years of age, and could speak and read Spanish. Pregnant women were excluded if they have mental retardation, twins, fetal malformation or a history of chronic hypertension, diabetes mellitus, sepsis or renal failure. Participants provided written informed consent. All study procedures were approved by the INMP in Lima, Peru, and the Office of Human Research Administration at the Harvard T.H. Chan School of Public Health, Boston, MA.

\section{Analytical population}

Information was collected from participants enrolled in the PrOMIS cohort from February 2012 to March 2014. After excluding 20 women due to missing information on migraine, a total of 2922 women were included in our analysis. The excluded participants were not different from the rest of the cohort in regards to sociodemographic or lifestyle characteristics.

\section{Migraine assessment}

Trained interviewers administered a Spanish-language questionnaire to determine migraine classification. Migraine and probable migraine status were classified based on the International Classification of Headache Disorders (ICHD)-III beta criteria [26]. Migraine was classified as participants fulfilling all 5 migraine diagnostic criteria. Probable migraine was designated if all 5 but one of the diagnostic criteria were fulfilled. Women fulfilling ICHD-III beta criteria for migraine or probable migraine when combined were classified as "any migraine."
Women not fulfilling ICHD-III beta criteria for either migraine or probable migraine were classified as nonmigraineurs.

\section{PTSD assessment}

PTSD was assessed using the PTSD Checklist-Civilian Version (PCL-C), a self-report measure with 17 items reflecting Diagnostic and Statistical Manual of Mental Disorders (DSM-IV) criteria [27]. For each item, participants were asked how bothered they were by a symptom over the past month on a 5-point Likert scale in regards to their most significant life event stressor. The total score on the PCL-C ranges from 17 to 85 . Recent data from our team support that a PCL-C score of 26 or higher on the Spanish-language version is associated with an $86 \%$ sensitivity and $63 \%$ specificity in diagnosing PTSD in a Peruvian population [28]. Further, we also examined PTSD using the established cutoff score of 44 or higher $[20,29,30]$.

\section{Other covariates}

Sociodemographic characteristics and information pertaining to depression status were collected from participants through structured questionnaires. Participants' age was classified as: $18-19,20-29,30-34$, or $\geq 35$ years old. Other sociodemographic covariates included: body mass index (BMI) based on self-reported pre-pregnancy weight and measured early pregnancy BMI $\quad<18.5$, 18.5-24.9, 25-29.9, >30 kg/m²), educational attainment $(\leq 6,7-12,>12$ years), maternal ethnicity (Mestizos of mixed Amerindian and European descent vs. others), employment status (employed vs. not employed), marital status (married or living with partner vs. other), difficulty paying for medical care (hard vs. not very hard), difficulty paying for the very basics (hard vs. not very hard), planned pregnancy (yes vs. no), parity (nulliparous vs. multiparous), lifetime intimate partner violence (yes vs. no), childhood abuse (no abuse, physical abuse only, sexual abuse only, both physical and sexual abuse), and gestational age in weeks at the time of interview. The presence of antepartum depression was ascertained using the 9 item Spanish-language Patient Health Questionnaire-9 (PHQ-9) that has been validated in this population [31-33]. The PHQ-9 assesses depressive symptoms over the previous 14 days. The PHQ-9 score is calculated by assigning a score of $0-3$ to the following response categories: "not at all," "several days," "more than half the days," "nearly every day." We defined presence of depression if participants had a PHQ-9 score $\geq 10$ [34]. Lifetime intimate partner violence was ascertained through questions adapted from the Demographic Health Survey Questionnaires and Modules: Domestic Violence Module [35] and the WHO Multi-Country Study on Violence Against Women [36], respectively. 


\section{Statistical analysis}

Sociodemographic and reproductive characteristics were examined using number (percent, \%) for categorical variables and mean ( \pm standard deviation [SD]) for continuous variables. Chi-square tests were used to evaluate differences in distribution of categorical variables, and analysis of variance (ANOVA) was used to evaluate mean differences for continuous variables. Multivariable logistic regressions were used to estimate odds ratios (OR) and 95\% confidence intervals (CI) of migraine in relation to PTSD.

Confounding factors were examined based on their hypothesized relationship with migraine and PTSD. Confounding was evaluated by entering potential confounders into a logistic regression model sequentially and comparing adjusted and unadjusted ORs. Final multivariable regression models included covariates that altered ORs by at least $10 \%$ or were considered a priori as potential confounders in the association between migraine and PTSD [37]. We examined the following covariates as potential confounders in the analyses: age, education, BMI, Mestizo ethnicity, marital status, employment, difficult paying for the basics or for medical care, parity, planned pregnancy, gestational age, childhood abuse, lifetime intimate partner violence, and depression. Prior studies have reported the comorbidity of depression and migraine [38, 39], including during pregnancy [18]. Given this, we repeated the analyses stratifying by maternal depression. In addition, some studies have used a PCL-C cutoff score of 44 to identify PTSD. Thus, we performed a sensitivity analysis using a PCL-C cutoff score of 44 or higher to diagnose PTSD. Reported $P$-values were two-sided and were statistically significant at $P \leq 0.05$. All analyses were performed using SPSS Statistics, Version 23.0 (IBM SPSS v23.0, Armonk, NY, USA).

\section{Results}

\section{Sociodemographic and reproductive characteristics}

The sociodemographic and reproductive characteristics of the study population are shown in Table 1. A total of 2922 pregnant women between 18 to 35 years old $($ mean $=28.12$ years; standard deviation $(\mathrm{SD})=6.31)$ were included in the analysis. The average gestational age at time of the interview was 9.23 weeks $(\mathrm{SD}=3.46)$. The majority of the participants were married or living with a partner (81.1\%), Mestizos (a race/ethnicity of mixed Amerindian and European descent; 75.2\%), unemployed (53.7\%), and with less than 12 years of education (59\%). The prevalence of any migraine was $33.5 \%$ (migraine $12.5 \%$; probable migraine $21.0 \%$ ). Those with migraine were more likely to be unemployed, have difficulties paying for basic necessities and medical care, identify as Mestizo, and have a history of child abuse and lifetime intimate partner violence (Table 1). Of the
2922 participants, $37.4 \%$ of the participants fulfilled criteria for PTSD. Participants with PTSD were less likely to identify as Mestizo and were more likely to have difficulties paying for the basics, have difficulties paying for medical care, have a history of lifetime intimate partner violence, and suffer from depression than those without a PTSD diagnosis (Additional file 1: Table S1).

\section{Migraine and PTSD}

A history of any migraine (migraine and probable migraine) was statistically significantly associated with increased odds of PTSD (OR = 2.50; 95\% CI: 2.14-2.93) (Table 2). After adjusting for sociodemographic confounders, women who suffered from any migraine had a 2.37-fold increased odds of PTSD (95\% CI: 2.02-2.79) as compared to women with no history of migraine. Further adjustment for lifetime intimate partner violence and depression status attenuated the magnitude of association but it remained significant $(\mathrm{OR}=1.97$; 95\% CI: 1.64-2.37). After adjusting for sociodemographic confounders, women with migraine had a 3.81-fold increased odds of PTSD (95\% CI: 3.00-4.82) as compared to nonmigraineurs, and the association remained significant after adjusting for lifetime intimate partner violence and depression status (OR $=2.85$; 95\% CI: 2.18-3.74). Participants with probable migraine had a 1.80 -fold increased odds of PTSD (95\% CI: 1.49-2.18) as compared to nonmigraineurs after adjusting for potential confounders. Further adjustment for depression status and lifetime intimate partner violence slightly attenuated the magnitude of association (OR $=1.61 ; 95 \%$ CI:1.30-1.99) (Table 1).

\section{Migraine and PTSD stratified by depression}

Finally, we explored the association of migraine and PTSD stratified by depression status (Table 3). In a multivariable adjusted model, women with any migraine (migraine and probable migraine) but without depression had a 1.93-fold increased odds of PTSD (95\% CI: 1.55-2.40) (Table 3) compared with the reference group (women without migraine or depression). Women with migraine but no depression had a 2.76-fold increased odds of PTSD (OR = 2.76; 95\% CI: 1.99-3.82) after adjusting for sociodemographic confounders compared with women who had neither condition. Pregnant women with probable migraine and no depression had a 1.62-fold increased odds of PTSD $(\mathrm{OR}=1.62,95 \% \mathrm{CI}$ : 1.99-3.82) compared with the reference. Compared to the reference group, participants suffering from depression and any migraine had an approximately 2.1-fold increased odds of PTSD (OR = 2.09; 95\% CI: 1.49-2.92) after adjusting for potential confounders. Women with migraine or probable migraine stratified by depression had a similar increase in likelihood of PTSD compared to non-migraineurs (migraine: $\mathrm{OR}=3.13$; 95\% CI: $1.91-5.11$; 
Table 1 Socio-demographic and reproductive characteristics of the study population according to types of migraine in Lima, Peru ( $N=2922)$

\begin{tabular}{|c|c|c|c|c|c|c|c|c|c|}
\hline \multirow[t]{2}{*}{ Characteristics } & \multicolumn{2}{|c|}{$\begin{array}{l}\text { All participants } \\
(N=2922)\end{array}$} & \multicolumn{2}{|c|}{$\begin{array}{l}\text { No migraine } \\
(N=1943)\end{array}$} & \multicolumn{2}{|c|}{$\begin{array}{l}\text { Probable migraine } \\
(N=613)\end{array}$} & \multicolumn{2}{|c|}{$\begin{array}{l}\text { Migraine } \\
(N=366)\end{array}$} & \multirow[t]{2}{*}{$P$-value } \\
\hline & $\bar{n}$ & $\%$ & $\bar{n}$ & $\%$ & $n$ & $\%$ & $n$ & $\%$ & \\
\hline Age (years) ${ }^{a}$ & \multicolumn{2}{|c|}{$28.12 \pm 6.31$} & \multicolumn{2}{|c|}{$28.30 \pm 6.31$} & \multicolumn{2}{|c|}{$27.76 \pm 6.30$} & \multicolumn{2}{|c|}{$27.76 \pm 6.27$} & 0.093 \\
\hline \multicolumn{10}{|l|}{ Age (years) } \\
\hline $18-19$ & 154 & 5.3 & 102 & 5.2 & 33 & 5.4 & 19 & 5.2 & \multirow[t]{4}{*}{0.549} \\
\hline $20-29$ & 1642 & 56.2 & 1068 & 55.0 & 359 & 58.6 & 215 & 58.7 & \\
\hline $30-34$ & 602 & 20.6 & 411 & 21.2 & 115 & 18.8 & 76 & 20.8 & \\
\hline$\geq 35$ & 524 & 17.9 & 362 & 18.6 & 106 & 17.3 & 56 & 15.3 & \\
\hline \multicolumn{10}{|l|}{ Education (years) } \\
\hline$\leq 6$ & 123 & 4.2 & 77 & 4.0 & 27 & 4.4 & 19 & 5.2 & \multirow[t]{3}{*}{0.142} \\
\hline $7-12$ & 1599 & 54.8 & 1058 & 54.5 & 356 & 58.4 & 185 & 50.7 & \\
\hline$>12$ & 1194 & 40.9 & 806 & 41.5 & 227 & 37.2 & 161 & 44.1 & \\
\hline \multicolumn{10}{|l|}{ Pre-pregnancy self-reported BMI } \\
\hline$<18.5$ & 30 & 1.2 & 18 & 1.1 & 9 & 1.7 & 3 & 1.0 & \multirow[t]{4}{*}{0.777} \\
\hline $18.5-24.9$ & 1298 & 53.3 & 865 & 54.1 & 270 & 51.8 & 163 & 51.9 & \\
\hline $25-29.9$ & 851 & 34.9 & 545 & 34.1 & 189 & 36.3 & 117 & 37.3 & \\
\hline$>30$ & 256 & 10.5 & 172 & 10.8 & 53 & 10.2 & 31 & 9.9 & \\
\hline \multicolumn{10}{|l|}{ Early pregnancy measured BMI } \\
\hline$<18.5$ & 54 & 1.9 & 26 & 1.4 & 23 & 3.8 & 5 & 1.4 & \multirow[t]{4}{*}{0.001} \\
\hline $18.5-24.9$ & 1405 & 48.6 & 935 & 48.6 & 278 & 45.9 & 192 & 53.0 & \\
\hline $25-29.9$ & 1073 & 37.1 & 707 & 36.7 & 240 & 39.6 & 126 & 34.8 & \\
\hline$>30$ & 361 & 12.5 & 257 & 13.4 & 65 & 10.7 & 39 & 10.8 & \\
\hline Mestizo ethnicity & 2194 & 75.2 & 1454 & 74.9 & 491 & 80.1 & 249 & 68.2 & $<0.001$ \\
\hline Married/living with a partner & 2360 & 81.1 & 1566 & 80.9 & 498 & 81.6 & 296 & 81.1 & 0.927 \\
\hline Employed & 1351 & 46.3 & 953 & 49.1 & 244 & 39.8 & 154 & 42.1 & $<0.001$ \\
\hline \multicolumn{10}{|l|}{ Difficulty paying for basics } \\
\hline Hard & 1449 & 49.6 & 905 & 46.6 & 340 & 55.5 & 204 & 55.7 & \multirow[t]{2}{*}{$<0.001$} \\
\hline Not very hard & 1471 & 50.4 & 1036 & 53.4 & 273 & 44.5 & 162 & 44.3 & \\
\hline \multicolumn{10}{|l|}{ Difficulty paying for medical care } \\
\hline Hard & 1532 & 52.6 & 937 & 48.4 & 372 & 60.7 & 223 & 61.1 & \multirow[t]{2}{*}{$<0.001$} \\
\hline Not very hard & 1382 & 47.4 & 999 & 51.6 & 241 & 39.3 & 142 & 38.9 & \\
\hline Nulliparous & 1425 & 48.9 & 971 & 50.2 & 289 & 47.2 & 165 & 45.1 & 0.129 \\
\hline Planned pregnancy & 1206 & 41.6 & 823 & 42.6 & 252 & 41.4 & 131 & 36.1 & 0.067 \\
\hline Gestational age at interview ${ }^{a}$ & \multicolumn{2}{|c|}{$9.23 \pm 3.46$} & $9.28 \pm$ & & 9.14 & & 9.11 & & 0.545 \\
\hline Intimate partner violence ${ }^{b}$ & 1064 & 36.5 & 648 & 33.4 & 243 & 39.8 & 173 & 47.7 & $<0.001$ \\
\hline Childhood abuse & & & & & & & & & \\
\hline No abuse & 827 & 28.3 & 590 & 30.4 & 161 & 26.3 & 76 & 20.8 & $<0.001$ \\
\hline Physical only & 1135 & 38.8 & 761 & 39.2 & 237 & 38.7 & 137 & 37.4 & \\
\hline Sexual only & 230 & 7.9 & 155 & 8.0 & 41 & 6.7 & 34 & 9.3 & \\
\hline Both physical and sexual & 730 & 25.0 & 437 & 22.5 & 174 & 28.4 & 119 & 32.5 & \\
\hline PTSD (PCL-C $\geq 26)$ & 1093 & 37.4 & 585 & 30.1 & 276 & 45.0 & 232 & 63.4 & $<0.001$ \\
\hline Depression (PHQ-9) & 799 & 27.6 & 435 & 22.6 & 193 & 31.7 & 171 & 47.2 & $<0.001$ \\
\hline
\end{tabular}

Due to missing data, percentages may not add up to $100 \%$

a mean \pm SD (standard deviation): How many weeks pregnant were you during your first prenatal care visit?

b Lifetime intimate partner violence

For continuous variables, $P$-value was calculated using the one-way ANOVA; for categorical variables, $P$-value was calculated using the Chi-square test $P$-values that are italicized are all $<0.05$ 
Table 2 Association between migraine and PTSD ${ }^{a}$ assessed by the PCL-C during pregnancy $(N=2922)$

\begin{tabular}{|c|c|c|c|c|c|c|c|c|}
\hline \multirow[t]{2}{*}{ Migraine Status } & \multicolumn{2}{|c|}{$\begin{array}{l}\text { No PTSD } \\
(N=1829)\end{array}$} & \multicolumn{6}{|c|}{$\begin{array}{l}\text { PTSD } \\
(N=1093)\end{array}$} \\
\hline & $n$ & $\%$ & $n$ & $\%$ & $\begin{array}{l}\text { Unadjusted OR } \\
(95 \% \mathrm{Cl})\end{array}$ & $\begin{array}{l}\text { Adjusted OR } \\
(95 \% \mathrm{Cl})^{\mathrm{b}}\end{array}$ & $\begin{array}{l}\text { Adjusted OR } \\
(95 \% \mathrm{Cl})^{c}\end{array}$ & $\begin{array}{l}\text { Adjusted OR } \\
(95 \% \mathrm{Cl})^{d}\end{array}$ \\
\hline No migraine & 1358 & 74.2 & 585 & 53.5 & Reference & Reference & Reference & Reference \\
\hline Any migraine & 471 & 25.8 & 508 & 46.5 & $2.50(2.14-2.93)$ & $2.37(2.02-2.79)$ & $2.30(1.95-2.71)$ & $1.97(1.64-2.37)$ \\
\hline \multicolumn{9}{|l|}{ Types of migraine } \\
\hline No migraine & 1358 & 74.2 & 585 & 53.5 & Reference & Reference & Reference & Reference \\
\hline Probable migraine & 337 & 18.4 & 276 & 25.3 & $1.90(1.58-2.29)$ & $1.80(1.49-2.18)$ & $1.76(1.45-2.14)$ & $1.61(1.30-1.99)$ \\
\hline Migraine & 134 & 7.3 & 232 & 21.2 & $4.02(3.18-5.08)$ & $3.81(3.00-4.82)$ & $3.65(2.86-4.66)$ & $2.85(2.18-3.74)$ \\
\hline
\end{tabular}

Abbreviations: $O R$ odds ratio, $\mathrm{Cl}$ confidence interval

a PTSD is defined as PCL-C score $\geq 26$

${ }^{b}$ Adjusted for age, marital status, difficulty paying for the very basics, and difficulty paying for medical care

c Adjusted for age, marital status, difficulty paying for the very basics, difficulty paying for medical care, and lifetime intimate partner violence

d Adjusted for age, marital status, difficulty paying for the very basics, difficulty paying for medical care, lifetime intimate partner violence, and depression status

probable migraine: $\mathrm{OR}=1.59 ; 95 \% \mathrm{CI} ; 1.07-2.35)$ (Table 3).

The results remained similar using a PCL-C cut-off score of 44 to identify PTSD (Additional file 2: Table S2). For example, after adjusting for confounders, women who suffered from any migraine had a 3.81-fold increased odds of PTSD (95\% CI: 2.76-5.26) as compared to women with no history of migraine. Further adjustment for lifetime intimate partner violence and depression status attenuated the magnitude of association, but it remained significant (OR: 2.67; 95\% CI: 1.87-3.82).

\section{Discussion}

In our cross-sectional study of pregnant Peruvian women, migraine (whether any migraine [migraine and probable migraine], migraine alone, or probable migraine alone) was associated with increased odds of PTSD. After adjusting for confounders including antepartum depression, women who reported any migraine had a 1.97-fold increased odds of PTSD (95\% CI: 1.64-2.37) compared to women with no history of migraine. In a multivariable adjusted model, women with probable migraine had a 1.61-fold increased odds of PTSD (95\% CI: 1.30-1.99), and women with migraine had a 2.85 -fold increased odds of PTSD (95\% CI: 2.18-3.74), compared to women without migraine (Table 2). In the presence of antepartum depression, women with probable migraine or migraine had increased odds of PTSD (probable migraine: $\mathrm{OR}=1.59 ; 95 \%$ CI: $1.07-2.35$; migraine: $\mathrm{OR}=3.13 ; 95 \%$ CI: 1.91-5.11) compared to non-migraineurs (Table 3).

Previous studies have shown significant comorbidities between migraine and PTSD. However, to our knowledge, this study is the first to evaluate the association between migraine and PTSD in pregnant women. Our current findings are comparable with prior studies of adult men and non-pregnant women. In a small clinic-based study of headache patients (including migraine or tension type headache; $N=80$ ), prevalence of PTSD-like symptomatology was similar to a comparison group of patients with masticatory muscle pain [40]. However, Peterlin et al. (2008) in their study of migraineurs attending an outpatient headache center demonstrated that PTSD was more frequently reported among chronic migraineurs than episodic migraineurs $(42.9 \%$ vs. $9.4 \%$, $p=0.0059$ ) [20]. In a general population study in 2011, Peterlin et al. reported that those with episodic migraine had a 3- to 4- fold increased odds of PTSD as compared to those without headaches after adjusting for confounders (lifetime prevalence: $\mathrm{OR}=3.07,95 \% \mathrm{CI}$ : 2.12 $4.46 ; 12$-month prevalence: $\mathrm{OR}=4.34,95 \% \mathrm{CI}: 2.73-$ 6.89) [41]. In a cross-sectional study in Turkey, migraine was associated with PTSD among university students $(\mathrm{OR}=10.16,95 \% \mathrm{CI}: 3.16-32.71, p=0.001)$ [42]. A recent study by Smitherman and Kolivas similarly found that those with migraine were almost twice as likely to fulfill diagnostic criteria for PTSD than nonmigraineurs $(25.7 \%$ vs. $14.2 \%, p<0.0001)$. Further, compared to those without migraine, migraineurs reported more traumatic events (3.0 vs. 2.4, $p<0.0001$ ) [21]. Despite differences in geographic location, population characteristics, and sociodemographics, previous findings consistently show comorbidity between migraine and PTSD.

Several potential biological and neurochemical mechanisms have been postulated for the association between migraine and PTSD. These include the biochemical markers serotonin, cortisol, and norepinephrine. Migraineurs have been shown to have imbalances of serotonin, a regulator of pain in the nervous system [43]. Serotonin levels decrease during a migraine attack, causing the trigeminal nerve to release neuropeptides and cause severe migraine pain [44]. PTSD has been previously associated with serotonin function $[45,46]$. The hypothalamic-pituitary-adrenal axis and 
Table 3 Association between migraine and PTSD ${ }^{a}$ during pregnancy ( $\left.N=2922\right)$ stratified by depression status

\begin{tabular}{|c|c|c|c|c|c|c|c|}
\hline \multirow[t]{2}{*}{$\begin{array}{l}\text { Migraine } \\
\text { Without Depression }\end{array}$} & \multicolumn{2}{|c|}{$\begin{array}{l}\text { No PTSD } \\
(N=1587)\end{array}$} & \multicolumn{3}{|c|}{$\begin{array}{l}\text { PTSD } \\
(N=507)\end{array}$} & \multirow[b]{2}{*}{$\begin{array}{l}\text { Adjusted OR } \\
(95 \% \mathrm{Cl})^{\mathrm{b}}\end{array}$} & \multirow[b]{2}{*}{$\begin{array}{l}\text { Adjusted OR } \\
(95 \% \mathrm{Cl})^{c}\end{array}$} \\
\hline & $n$ & $\%$ & $n$ & $\%$ & $\begin{array}{l}\text { Unadjusted OR } \\
(95 \% \mathrm{Cl})\end{array}$ & & \\
\hline No migraine & 1191 & 75.0 & 297 & 58.6 & Reference & Reference & Reference \\
\hline Any migraine & 396 & 25.0 & 210 & 41.4 & $2.13(1.72-2.62)$ & $1.99(1.61-2.46)$ & $1.93(1.55-2.40)$ \\
\hline \multicolumn{8}{|l|}{ Types of migraine } \\
\hline No migraine & 1191 & 75.0 & 297 & 58.6 & Reference & Reference & Reference \\
\hline Probable migraine & 286 & 18.0 & 129 & 25.4 & $1.81(1.42-2.31)$ & $1.67(1.31-2.15)$ & $1.62(1.25-2.08)$ \\
\hline Migraine & 110 & 6.9 & 81 & 16.0 & $2.95(2.16-4.04)$ & $2.81(2.04-3.86)$ & $2.76(1.99-3.82)$ \\
\hline \multirow[t]{2}{*}{$\begin{array}{l}\text { Migraine } \\
\text { With Depression }\end{array}$} & \multicolumn{2}{|c|}{$\begin{array}{l}\text { No PTSD } \\
(N=224)\end{array}$} & \multicolumn{2}{|c|}{$\begin{array}{l}\text { PTSD } \\
(N=575)\end{array}$} & & & \\
\hline & $n$ & $\%$ & $n$ & $\%$ & $\begin{array}{l}\text { Unadjusted OR } \\
(95 \% \mathrm{Cl})\end{array}$ & $\begin{array}{l}\text { Adjusted OR } \\
(95 \% \mathrm{Cl})^{\mathrm{b}}\end{array}$ & $\begin{array}{l}\text { Adjusted OR } \\
(95 \% \mathrm{Cl})^{\mathrm{C}}\end{array}$ \\
\hline No migraine & 152 & 67.9 & 283 & 49.2 & Reference & Reference & Reference \\
\hline Any migraine & 72 & 32.1 & 292 & 50.8 & $2.18(1.57-3.01)$ & $2.13(1.53-2.96)$ & 2.09 (1.49-2.92) \\
\hline \multicolumn{8}{|l|}{ Types of migraine } \\
\hline No migraine & 152 & 67.9 & 283 & 49.2 & Reference & Reference & Reference \\
\hline Probable migraine & 49 & 21.9 & 144 & 25.0 & $1.58(1.08-2.31)$ & $1.58(1.07-2.32)$ & $1.59(1.07-2.35)$ \\
\hline Migraine & 23 & 10.3 & 148 & 25.7 & $3.46(2.14-5.59)$ & $3.29(2.03-5.34)$ & $3.13(1.91-5.11)$ \\
\hline
\end{tabular}

Abbreviations: $O R$ odds ratio, $\mathrm{Cl}$ confidence interval

a PTSD is defined as PCL-C score $\geq 26$

${ }^{\mathrm{b}}$ Adjusted for age, marital status, difficulty paying for the very basics, and difficulty paying for medical care

c Adjusted for age, marital status, difficulty paying for the very basics, difficulty paying for medical care, and lifetime intimate partner violence

related cortisol levels have also been associated with migraine and PTSD [3, 47-49]. Additionally, decreased levels of cortisol and elevated levels of pro-inflammatory cytokines (e.g. tumor necrosis factor-alpha, interleukin-6) in patients with PTSD have been suggested to be linked to migraine [50, 51]. Videlock et al. (2008) found that norepinephrine plasma levels are lower in those with PTSD when compared to individuals without PTSD [52]. Migraine patients also may have lower levels of plasma and platelet norepinephrine [53]. Mental health during pregnancy is of particular interest given the high burden of violence in this population $[24,54]$. A previous study in the same cohort found $70 \%$ of participants had a history of childhood abuse and $36.7 \%$ had a history of intimate partner violence, and their abuse history was associated with an increased risk of migraine [54]. PTSD is prevalent during pregnancy and may increase postpartum if it is not identified [55]. Although a large percentage of the population suffers from migraines, particularly those of reproductive age, the mechanisms underlying the development of migraines and PTSD have yet to be fully understood [56].

Our study has several strengths, including a large sample size and a population with a high prevalence of migraine and PTSD. However, some limitations should also be considered. First, this cross-sectional study does not establish temporal relationships between migraine and PTSD. Second, the study was conducted among lowincome pregnant women in Peru; thereby, warranting caution when generalizing our study to other pregnant women. Lastly, migraine and PTSD diagnoses were established using self-reported questionnaires. Thus, we cannot exclude the possibility that PTSD and migraine status were underreported in our study. Studies that systematically use screening and confirmatory diagnostic evaluations will greatly attenuate concerns about misclassification of PTSD and migraine diagnoses in epidemiological studies [20,21].

\section{Conclusions}

Individually, migraine [57-59] and PTSD [60, 61] each carry a high individual, societal, and economic burden. Our study found an association between migraine and PTSD, even after adjusting for antepartum depression. Furthermore, our findings extend the body of literature on the increased risk of PTSD in those with migraine to include those with probable migraine and pregnant women. Taken together, these findings support the need for additional research on the association between migraine and PTSD, including in pregnant women, as well 
as the need for research evaluating potential treatment implications of this comorbidity.

\section{Additional files}

Additional file 1: Table S1. Socio-demographic and reproductive characteristics of the study population according to PTSD ${ }^{\text {a }}$ in Lima, Peru $(N=2922)$. (DOCX $36 \mathrm{~kb})$

Additional file 2: Table S2. Association between migraine and PTSD ${ }^{a}$ during pregnancy $(N=2922)$. (DOCX $31 \mathrm{~kb})$

\section{Abbreviations}

ANOVA: Analysis of variance; BMI: Body mass index; Cl: Confidence interval: DSM-IV: Diagnostic and Statistical Manual of Mental Disorders; ICHD: International Classification of Headache Disorders; IL: Interleukin; INMP: Instituto Nacional Materno Perinatal; OR: Odds ratio; PCL-C: PTSD Checklist-Civilian Version; PHQ-9: Patient Health Questionnaire-9; PrOMIS: Pregnancy Outcomes, Maternal and Infant Study; PTSD: Posttraumatic stress disorder; SD: Standard deviation

\section{Acknowledgements}

The authors wish to thank the dedicated staff members of Asociacion Civil Proyectos en Salud (PROESA), Peru, and Instituto Especializado Materno Perinatal, Peru, for their expert technical assistance with this research.

\section{Funding}

This research was supported by awards from the National Institutes of Health $(\mathrm{NIH})$, National Institute of Minority Health and Health Disparities (T37-MD001449), and the Eunice Kenney Shriver National Institute of Child Health and Human Development (R01-HD-059835). The NIH had no further role in study design; in the collection, analysis, and interpretation of data; in the writing of the report; and in the decision to submit the paper for publication.

\section{Authors' contributions}

$B L P, B G, L E F$, and MAW conceived and designed the study. RPH, CA, and LEF analyzed data and drafted the manuscript. All authors interpreted the data, critically revised the draft for important intellectual content, and gave final approval of the manuscript to be published.

\section{Competing interests}

Dr. Gelaye has consulted for Egalet Corporation for an unrelated project. Dr. Peterlin has unrelated investigator-initiated grant support from Egalet Corporation and the Landenberger Foundation. The other authors have no conflicts of interest to disclose.

\section{Ethics approval and consent to participate}

Participants provided written informed consent. All study procedures were approved by the INMP in Lima, Peru, and the Office of Human Research Administration at the Harvard T.H. Chan School of Public Health, Boston, MA.

\section{Author details}

${ }^{1}$ Department of Epidemiology, Harvard T. H. Chan School of Public Health, 677 Huntington Ave, K501, Boston, MA 02115, USA. ${ }^{2}$ Multidisciplinary International Research Training Program, Department of Epidemiology, Harvard T. H. Chan School of Public Health, Boston, MA, USA. ${ }^{3}$ Departamento de Rehabilitación, Hospital del Trabajador, Santiago, Chile. ${ }^{4}$ Global Health and Social Medicine, Harvard Medical School, Boston, MA, USA. ${ }^{5}$ Universidad Peruana de Ciencias Aplicadas, Lima, Peru. ${ }^{6}$ Asociación Civil PROESA, Lima, Peru. ${ }^{7}$ Department of Neurology, Johns Hopkins School of Medicine, Baltimore, MD, USA.

Received: 27 April 2017 Accepted: 7 June 2017 Published online: 06 July 2017

\section{References}

1. Smitherman TA, Burch R, Sheikh H, Loder E (2013) The prevalence, impact, and treatment of migraine and severe headaches in the United States: a review of statistics from national surveillance studies. Headache 53(3):427-436. doi:10.1111/head.12074

2. Lipton R, Bigal M, Diamond M, Freitag F, Reed M, Stewart W, Group AA (2007) Migraine prevalence, disease burden, and the need for preventive therapy. Neurology 68(5):343-349

3. Peterlin B, Nijjar S, Tietjen G (2011) Post-traumatic stress disorder and migraine: epidemiology, sex differences, and potential mechanisms. Headache 51(6):860-868. doi:10.1111/j.1526-4610.2011.01907.x

4. Sanchez SE, Qiu C, Williams MA, Lam N, Sorensen TK (2008) Headaches and migraines are associated with an increased risk of preeclampsia in Peruvian women. Am J Hypertens 21(3):360-364. doi:10.1038/ajh.2007.46

5. Adeney KL, Williams MA (2006) Migraine headaches and preeclampsia: an epidemiologic review. Headache 46(5):794-803. doi:10.1111/j.1526-4610. 2006.00432.x

6. Cripe SM, Frederick IO, Qiu C, Williams MA (2011) Risk of preterm delivery and hypertensive disorders of pregnancy in relation to maternal co-morbid mood and migraine disorders during pregnancy. Paediatr Perinat Epidemiol 25(2):116-123. doi:10.1111/j.1365-3016.2010.01182.x

7. Sanchez SE, Williams MA, Pacora PN, Ananth CV, Qiu C, Aurora SK, Sorensen TK (2010) Risk of placental abruption in relation to migraines and headaches. BMC Womens Health 10:30. doi:10.1186/1472-6874-10-30

8. Wabnitz A, Bushnell C (2015) Migraine, cardiovascular disease, and stroke during pregnancy: systematic review of the literature. Cephalalgia 35(2):132139. doi:10.1177/0333102414554113

9. Bushnell CD, Jamison M, James AH (2009) Migraines during pregnancy linked to stroke and vascular diseases: US population based case-control study. BMJ 338:b664. doi:10.1136/bmj.b664

10. James A, Bushnell C, Jamison M, Myers E (2005) Incidence and risk factors for stroke in pregnancy and the Puerperium. Obstet Gynaecol 106(3):509-516

11. Scott CA, Bewley S, Rudd A, Spark P, Kurinczuk JJ, Brocklehurst P, Knight M (2012) Incidence, risk factors, management, and outcomes of stroke in pregnancy. Obstet Gynaecol 120(2 Pt 1):318-324. doi:10.1097/AOG. Ob013e31825f287c

12. Breslau N, Davis G (1992) Migraine, major depression and panic disorder: a prospective epidemiologic study of young adults. Cephalalgia 12(2):85-90

13. Breslau N, Schultz L, Stewart W, Lipton R, Welch K (2001) Headache types and panic disorder: directionality and specificity. Neurology 56(3):350-354

14. Breslau NDG, Schultz LR, Peterson EL (1994) Joint 1994 Wolff award presentation. Migraine and major depression: a longitudinal study. Headache 34(7):387-393

15. Lanteri-Minet M, Radat F, Chautard MH, Lucas C (2005) Anxiety and depression associated with migraine: influence on migraine subjects' disability and quality of life, and acute migraine management. Pain 118(3): 319-326. doi:10.1016/j.pain.2005.09.010

16. Serafini G, Pompili M, Innamorati M, Gentile G, Borro M, Lamis DA, Lala N, Negro A, Simmaco M, Girardi P, Martelletti P (2012) Gene variants with suicidal risk in a sample of subjects with chronic migraine and affective temperamental dysregulation. Eur Rev Med Pharmacol Sci 16(10):1389-1398

17. Cripe SM, Sanchez S, Lam N, Sanchez E, Ojeda N, Tacuri S, Segura C, Williams MA (2010) Depressive symptoms and migraine comorbidity among pregnant Peruvian women. J Affect Disord 122(1-2):149-153. doi:10.1016/j. jad.2009.07.014

18. Orta OR, Gelaye B, Qiu C, Stoner L, Williams MA (2015) Depression, anxiety and stress among pregnant migraineurs in a pacific-northwest cohort. J Affect Disord 172:390-396. doi:10.1016/j.jad.2014.10.032

19. Friedman LE, Gelaye B, Rondon MB, Sanchez SE, Peterlin BL, Williams MA (2016) Association of Migraine Headaches with Suicidal Ideation among Pregnant Women in Lima, Peru. Headache 56(4):741-749. doi:10.1111/head.12793

20. Peterlin BL, Tietjen G, Meng S, Lidicker J, Bigal M (2008) Post-traumatic stress disorder in episodic and chronic migraine. Headache 48(4):517-522. doi:10. 1111/j.1526-4610.2008.00917.x

21. Smitherman TA, Kolivas ED (2013) Trauma exposure versus posttraumatic stress disorder: relative associations with migraine. Headache 53(5):775-786. doi:10.1111/head.12063

22. Barrios YV, Sanchez SE, Nicolaidis C, Garcia PJ, Gelaye B, Zhong Q, Williams MA (2015) Childhood abuse and early menarche among Peruvian women. J Adolesc Health 56(2):197-202. doi:10.1016/j.jadohealth.2014.10.002

23. Gelaye B, Barrios YV, Zhong QY, Rondon MB, Borba CP, Sanchez SE, Henderson DC, Williams MA (2015) Association of poor subjective sleep quality with suicidal ideation among pregnant Peruvian women. Gen Hosp Psychiatry 37(5):441-447. doi:10.1016/j.genhosppsych.2015.04.014 
24. Barrios YV, Gelaye B, Zhong Q, Nicolaidis C, Rondon MB, Garcia PJ, Sanchez PA, Sanchez SE, Williams MA (2015) Association of childhood physical and sexual abuse with intimate partner violence, poor general health and depressive symptoms among pregnant women. Plos One 10(1):e0116609. doi:10.1371/journal.pone.0116609

25. Zhong QY, Wells A, Rondon MB, Williams MA, Barrios YV, Sanchez SE, Gelaye B (2016) Childhood abuse and suicidal ideation in a cohort of pregnant Peruvian women. Am J Obstet Gynecol 215(4):e501-e508. doi:10.1016/j.ajog. 2016.04.052

26. Society HCCotIH (2013) The International classification of headache disorders, 3rd edition (beta version). Cephalalgia 33(9):629-808. doi:10.1177/ 0333102413485658

27. Weathers F, Huska J, Keane T (1991) PCL-C for DSM-IV. National Center for PTSD-Behavioral Science Division, Boston

28. Gelaye B, Zheng Y, Medina-Mora ME, Rondon MB, Sanchez SE, Williams MA (2017) Validity of the posttraumatic stress disorders (PTSD) checklist in pregnant women. BMC Psychiatry 17(1):179. doi:10.1186/s12888-017-1304-4

29. Blanchard E, Jones-Alexander J, Buckley T, Forneris C (1996) Psychometric properties of the PTSD checklist (PCL). Behav Res Ther 34(8):669-673

30. Peterlin BL, Tietjen GE, Brandes $J$, Rubin SM, Drexler E, Lidicker JR, Meng $S$ (2009) Posttraumatic stress disorder in migraine. Headache 49(4):541-551. doi:10.1111/j.1526-4610.2009.01368.x

31. Kroenke K, Spitzer R, Williams J (2001) The PHQ-9: validity of a brief depression severity measure. J Gen Intern Med 16(9):606-613

32. Wulsin L, Somoza E, Heck J (2002) The feasibility of using the Spanish PHQ-9 to screen for depression in primary care in Honduras. Prim Care Clin Psychiatry 4(5):191-195

33. Zhong Q, Gelaye B, Fann JR, Sanchez SE, Williams MA (2014) Cross-cultural validity of the Spanish version of $\mathrm{PHQ}-9$ among pregnant Peruvian women: a Rasch item response theory analysis. J Affect Disord 158:148-153. doi:10. 1016/j.jad.2014.02.012

34. Kroenke K, Spitzer RL, Williams JB, Lowe B (2010) The Patient health questionnaire somatic, anxiety, and depressive symptom scales: a systematic review. Gen Hosp Psychiatry 32(4):345-359. doi:10.1016/j. genhosppsych.2010.03.006

35. The Demographic and Health Surveys (DHS) Program (2005) "Demographic Health Survey questionnaires and modules: Domestic violence module." Available: http://dhsprogram.com/publications/publication-dhsqm-dhsquestionnaires-and-manuals.cfm

36. Garcia-Moreno C, Jansen HAFM, Ellsberg M, Heise L, Watts CH (2006) Prevalence of intimate partner violence: findings from the WHO multicountry study on women's health and domestic violence. Lancet 368(9543): 1260-1269. doi:10.1016/s0140-6736(06)69523-8

37. Rothman KJ, Greenland S, Lash TL (2012) Modern Epidemiology, 3rd Edition. Lippincott, Williams \& Wilkins, Philadelphia, PA

38. Breslau N, Lipton R, Stewart W, Schultz L, Welch K (2003) Comorbidity of migraine and depression: investigating potential etiology and prognosis. Neurology 60(8):1308-1312

39. Breslau N, Schultz L, Stewart W, Lipton R, Lucia V, Welch K (2000) Headache and major depression: is the association specific to migraine? Neurology 54(2):308-313

40. de Leeuw R, Schmidt JE, Carlson CR (2005) Traumatic stressors and posttraumatic stress disorder symptoms in headache patients. Headache 45(10): 1365-1374. doi:10.1111/j.1526-4610.2005.00269.x

41. Peterlin BL, Rosso AL, Sheftell FD, Libon DJ, Mossey JM, Merikangas KR (2011) Post-traumatic stress disorder, drug abuse and migraine: new findings from the National Comorbidity Survey Replication (NCS-R). Cephalalgia 31(2):235-244. doi:10.1177/0333102410378051

42. Balaban H, Semiz M, Senturk IA, Kavakci O, Cinar Z, Dikici A, Topaktas S (2012) Migraine prevalence, alexithymia, and post-traumatic stress disorder among medical students in Turkey. J Headache Pain 13(6):459-467. doi:10. 1007/s10194-012-0452-7

43. Hamel E (2007) Serotonin and migraine: biology and clinical implications. Cephalalgia 27(11):1293-1300

44. Kalaycioglu E, Gokdeniz T, Aykan AC, Gursoy MO, Gul I, Ayhan N, Celik S (2014) Evaluation of right ventricle functions and serotonin levels during headache attacks in migraine patients with aura. Int J Card Imaging 30(7): 1255-1263. doi:10.1007/s10554-014-0456-2

45. Juang K, Yang C (2014) Psychiatric comorbidity of chronic daily headache: focus on traumatic experiences in childhood, post-traumatic stress disorder and suicidality. Curr Pain Headache Rep 18(4):405. doi:10.1007/s11916-014-0405-8
46. Xie P, Kranzler HR, Poling J, Stein MB, Anton RF, Brady K, Weiss RD, Farrer L, Gelernter J (2009) Interactive effect of stressful life events and the serotonin transporter 5-HTTLPR genotype on posttraumatic stress disorder diagnosis in 2 independent populations. Arch Gen Psychiatry 66(11):1201-1209. doi: 10.1001/archgenpsychiatry.2009.153

47. Peres M, MSd R, Seabra M, Tufik S, Abucham J, Cipolla-Neto J, Silberstein S, Zukerman E (2001) Hypothalamic involvement in chronic migraine. J Neurol Neurosurg Psychiatry 71(6):747-751

48. Daskalakis NP, Lehrner A, Yehuda R (2013) Endocrine aspects of posttraumatic stress disorder and implications for diagnosis and treatment. Endocrinol Metab Clin N Am 42(3):503-513. doi:10.1016/j.ecl.2013.05.004

49. Morris MC, Compas BE, Garber J (2012) Relations among posttraumatic stress disorder, comorbid major depression, and HPA function: a systematic review and meta-analysis. Clin Psychol Rev 32(4):301-315. doi:10.1016/j.cpr.2012.02.002

50. Gill J, Vythilingam M, Page GG (2008) Low cortisol, high DHEA, and high levels of stimulated TNF-alpha, and IL-6 in women with PTSD. J Trauma Stress 21(6):530-539. doi:10.1002/jts.20372

51. Sarchielli P, Alberti A, Baldi A, Coppola F, Rossi C, Pierguidi L, Floridi A, Calabresi P (2006) Proinflammatory cytokines, adhesion molecules, and lymphocyte integrin expression in the internal jugular blood of migraine patients without aura assessed ictally. Headache 46(2):200-207. doi:10.1111/ j.1526-4610.2006.00337.x

52. Videlock EJ, Peleg T, Segman R, Yehuda R, Pitman RK, Shalev AY (2008) Stress hormones and post-traumatic stress disorder in civilian trauma victims: a longitudinal study. Part II: the adrenergic response. Int J Neuropsychopharmacol 11(3):373-380. doi:10.1017/S1461145707008139

53. Martínez F, Castillo J, Pardo J, Lema M, Noya M (1993) Catecholamine levels in plasma and CSF in migraine. J Neurol Neurosurg Psychiatry 56(10):1119-1121

54. Gelaye B, Do N, Avila S, Carlos Velez J, Zhong QY, Sanchez SE, Peterlin BL, Williams MA (2016) Childhood abuse, intimate partner violence and risk of migraine among pregnant women: an epidemiologic study. Headache 56(6):976-986. doi:10.1111/head.12855

55. Yildiz PD, Ayers S, Phillips $L$ (2017) The prevalence of posttraumatic stress disorder in pregnancy and after birth: a systematic review and metaanalysis. J Affect Disord 208:634-645. doi:10.1016/j.jad.2016.10.009

56. Banhidy F, Acs N, Horvath-Puho E, Czeizel AE (2007) Pregnancy complications and delivery outcomes in pregnant women with severe migraine. Eur J Obstet Gynecol Reprod Biol 134(2):157-163. doi:10.1016/j. ejogrb.2006.08.025

57. Lipton RBSW, Scher Al (2001) Epidemiology and economic impact of migraine. Curr Med Res Opin 17(Suppl 1):S4-12

58. Stewart W, Ricci J, Chee E, Morganstein D, Lipton R (2003) Lost productive time and cost due to common pain conditions in the US workforce. JAMA 290(18):2443-2454

59. Stovner L, Hagen K, Jensen R, Katsarava Z, Lipton R, Scher A, Steiner T, Zwart JA (2007) The global burden of headache: a documentation of headache prevalence and disability worldwide. Cephalalgia 27(3):193-210. doi:10.1111/j.1468-2982.2007.01288.x

60. Atwoli L, Stein DJ, Koenen KC, MCLaughlin KA (2015) Epidemiology of posttraumatic stress disorder: prevalence, correlates and consequences. Curr Opin Psychiatry 28(4):307-311. doi:10.1097/YCO.0000000000000167

61. Kalia M (2002) Assessing the economic impact of stress: the modern day hidden epidemic. Metabolism 51(6):49-53. doi:10.1053/meta.2002.33193

\section{Submit your manuscript to a SpringerOpen ${ }^{\circ}$ journal and benefit from:}

- Convenient online submission

- Rigorous peer review

- Open access: articles freely available online

- High visibility within the field

Retaining the copyright to your article

Submit your next manuscript at $>$ springeropen.com 